\title{
Níveis de proteína bruta em dietas comerciais para suínos em crescimento e terminação ${ }^{1}$
}

\section{Messias Alves da Trindade Neto², José Aparecido Moreira ${ }^{3}$, Dirlei Antonio Berto ${ }^{4}$, Willian Correa Miguel ${ }^{2}$, Eliana Aparecida Schammass ${ }^{5}$}

\author{
1 Trabalho realizado com o apoio da Ajinomoto Biolatina Indústria e Comércio Ltda. \\ 2 Departamento de Nutrição e Produção Animal da FMVZ-USP, Campus de Pirassununga, Rua Duque de Caxias Norte, 225, CEP: 13635-900 - \\ Pirassununga - SP \\ ${ }^{3}$ Biólogo. \\ ${ }^{4}$ Departamento de Produção e Exploração Animal, FMVZ, UNESP/Botucatu, SP. \\ 5 Instituto de Zootecnia - Rua Heitor Penteado 56, Nova Odessa, SP, CEP: 13460-000.
}

RESUMO - Avaliaram-se quatro níveis de proteína bruta (PB) em dietas consideradas comerciais fornecidas a suínos machos castrados nas fases de crescimento e terminação. Foram utilizados 48 machos castrados de mesma linhagem genética, com pesos iniciais de 30,8 \pm 0,12 kg (fase de crescimento) e 61,2 \pm 0,89 $\mathrm{kg}$ (fase de terminação), segregados no sistema de produção. Os animais foram distribuídos em delineamento experimental de blocos ao acaso, compostos de quatro tratamentos (níveis de PB) e seis repetições e dois animais por unidade experimental. Os níveis de PB testados foram 19,5; 18,0; 16,5 e $15,0 \%$ na fase crescimento e 18,0; 16,$5 ; 15,0$ e 13,5\% na fase terminação. Na fase crescimento, não foram constatadas diferenças no desempenho dos machos castrados. Independentemente do nível de PB na dieta, as exigências nutricionais foram atendidas, não obstante, a dieta com 16,5\% PB indicou maior viabilidade econômica, calculada como margem bruta decorrente da alimentação. Semelhante à fase de crescimento, na fase de terminação os níveis de PB da dieta não promoveram diferenças no desempenho e nas características de carcaça dos animais ao abate. Ao considerar a margem bruta atribuída à alimentação, a dieta com 15,0\% PB permitiria maior retorno econômico no período correspondente ao intervalo dos 60 aos $100 \mathrm{~kg}$. A variação da proteína dietética com a suplementação dos principais aminoácidos não prejudicou o desempenho de suínos machos castrados nas fases de crescimento e terminação criados em condições desejáveis de saúde, segregados, em sistema de criação comercial. Pequenas variações entre aminoácidos não prejudicam o desempenho de suínos machos castrados nas fases de crescimento e terminação, desde que as exigências de lisina digestível e dos demais aminoácidos limitantes sejam mantidas próximas às relações mínimas atualmente indicadas.

Palavras-chave: carcaça, criação segregada, lisina digestível, nível de proteína

\section{Crude protein levels in commercial diets of growing and finishing barrows}

\begin{abstract}
It was evaluated four crude protein (CP) levels in diets considered as commercial fed to barrows in the growing and finishing phases. A total of 48 barrows, from the same genetic strain, averaging initial weights of $30.8 \pm 0.12 \mathrm{~kg}$ (growing phase) and $61.2 \pm-0.89 \mathrm{~kg}$ (finishing phase), segregated in the production system, was used. The animals were allotted to randomized blocks design, composed of four treatment (level of CP) and six replications and two animals per experimental unit. The CP levels tested were: 19.5, 18.0, 16.5, and $15.0 \%$ in growing and 18.0, $16.5,15.0$ and $13.5 \%$ in finishing phases. There was no difference in the growing phase of barrows performance. Independently of the dietary CP levels, the nutritional requirements were supplied, in spite of the diet with $16.5 \%$ CP indicated greater economic viability, calculated as gross margin due to the feed. Similar to the growing phase, there were no differences among CP levels on performance and carcass characteristics of finishing barrows at slaughter. The gross margin due to the feed indicated that $15.0 \% \mathrm{CP}$ in the diet offered greater economic gain for barrows from 60 to $100 \mathrm{~kg}$. The results indicate that dietary protein changes, with main principal amino acids supplied not impaired the barrows performance. The creation and segregation conditions of commercial farm system in growing and finishing phases need considerations. Small variations between amino acids did not affect performance of barrows in the growing and finishing phases if the requirements of digestible lysine and others amino acids are maintained close to the indicated minimal relation.
\end{abstract}

Key Words: carcass, digestible lysine, protein level, segregate breed 


\section{Introdução}

A proteína bruta (PB) dietética pode ser reduzida com a suplementação dos aminoácidos industriais para que as relações entre aqueles considerados essenciais sejam mantidas, no conceito da proteína ideal (Figueroa et al., 2002; Kerr et al., 2003b; Otto et al., 2003). Nesse caso, os aminoácidos industriais lisina, treonina e metionina tornam-se alternativas para flexibilização do custo das rações (Tuitoek et al., 1997; Shriver et al., 2003) na indústria e/ou unidades de produção de suínos e aves. A redução dos níveis de PB da dieta com a suplementação dos principais aminoácidos pode ser economicamente viável (Shriver et al., 2003), sobretudo quando há constante valorização de ingredientes protéicos, como tem ocorrido com o farelo de soja no mercado brasileiro e internacional.

Além dos benefícios diretos sobre a produção, ao diminuir a proteína dietética, preservando-se a relação entre os principais aminoácidos, reduzem-se as perdas fecais e urinárias de nitrogênio e os impactos negativos dos dejetos no meio ambiente (Otto et al., 2003; Kerr et al., 2003b; Shriver et al., 2003).

Em média, a redução de 2,0 a 4,0\% da PB de uma dieta suplementada com os principais aminoácidos, além de não ocasionar prejuízos ao desempenho do suíno, pode reduzir 20,0 a 40,0\% da excreção diária de nitrogênio nas fases de crescimento e terminação (Jongbloed \& Lenis, 1992; Figueroa et al., 2002; Otto et al., 2003; Kerr et al., 2003a,b; Shriver et al., 2003).

A magnitude da influência dos níveis dietéticos de $\mathrm{PB}$ sobre o desempenho e a carcaça depende do potencial genético do suíno, portanto, aqueles com maior deposição muscular são mais sensíveis às variações dos níveis protéicos. Nesse caso, o genótipo pode ter a influência do ambiente de criação e juntos podem alterar o custo total de produção, contribuindo para aumentar a produtividade e reduzir a perda de nutrientes no meio ambiente, onde passam a atuar como poluentes.

As condições higiênicas do ambiente de criação podem determinar o estado imunológico do suíno e interferir na deposição protéica durante todas as fases do crescimento. O suíno livre dos principais patógenos pode apresentar maior eficiência na taxa diária de deposição protéica (Williams et al., 1997a,b), contudo, em condições adversas, pode perder até $40 \%$ em eficiência de ganho muscular. Segundo Stahley (1993), isso significaria perda de até $20 \%$ no rendimento de carcaça.

Em condições sanitárias indesejáveis, o suíno, exposto a antígenos patogênicos ou não, pode demandar produção de anticorpos e liberação de substâncias ativadoras do sistema imunológico. A citocina liberada nessas condições, por exemplo, causa alterações no metabolismo da proteína muscular e tem ação inibitória de hormônios anabólicos. Segundo Williams et al. (1997a,b), o custo da ativação e liberação desta substância tem implicações negativas no processo de síntese protéica e acúmulo de massa muscular esquelética do suíno durante o crescimento.

Neste estudo, avaliaram-se níveis de PB em dietas comerciais suplementadas com os principais aminoácidos essenciais para suínos machos castrados de linhagem específica em fase de crescimento e terminação.

\section{Material e Métodos}

O estudo foi realizado nos meses de janeiro a maio, no Laboratório Experimental de Suínos do Pólo Regional Centro-Sul, em Piracicaba, antiga Estação de Avaliação de Suínos da Secretaria de Agricultura do Estado de São Paulo.

Em dois ensaios simultâneos com animais nas fases de crescimento e terminação, foram utilizados 48 machos castrados com peso médio inicial de $30,8 \mathrm{~kg}$ na fase de crescimento e 61,2 kg na fase de terminação. Os animais utilizados eram resultantes de cruzamentos entre reprodutores e matrizes de linhagem comercial, selecionados para produção de carne e oriundos de granja livre de doenças, segundo normas definidas pela Secretaria Nacional de Defesa Agropecuária do Ministério da Agricultura e Reforma Agrária.

Os animais foram distribuídos em delineamento de blocos ao acaso, com quatro tratamentos, seis repetições e dois animais por unidade experimental. A formação dos blocos foi realizada de acordo com o peso inicial dos animais e o controle experimental foi feito ao início e final do período experimental. As fases consideradas foram dos 30 aos $60 \mathrm{~kg}$ e dos 60 aos $95 \mathrm{~kg}$.

Os tratamentos utilizados foram dietas com níveis de 19,5; 18,0; 16,5 e 15,0\% de PB na fase de crescimento e 18,0; 16,5; 15,0 e 13,5\% de PB na fase de terminação. As dietas experimentais foram elaboradas conforme orientações de Rostagno et al. (2000) para que fossem asseguradas as exigências e relações mínimas entre lisina, treonina, metionina e triptofano em cada fase da criação (Tabela 1). À medida que se reduziu o nível de proteína, suplementaram-se os principais aminoácidos buscando sempre o custo mínimo para cada dieta.

Alimentação e água foram oferecidas à vontade. A ração, armazenada em recipiente individual junto a cada baia, era fornecida em diversos horários, o último à noite, de modo a não privar os animais do alimento.

Os animais foram alojados em baias de 2,00 × 1,00 m, construídas em estrutura metálica sobre piso de cimento, 
Tabela 1 - Composição centesimal de ingrediente e nutricional calculada das dietas experimentais

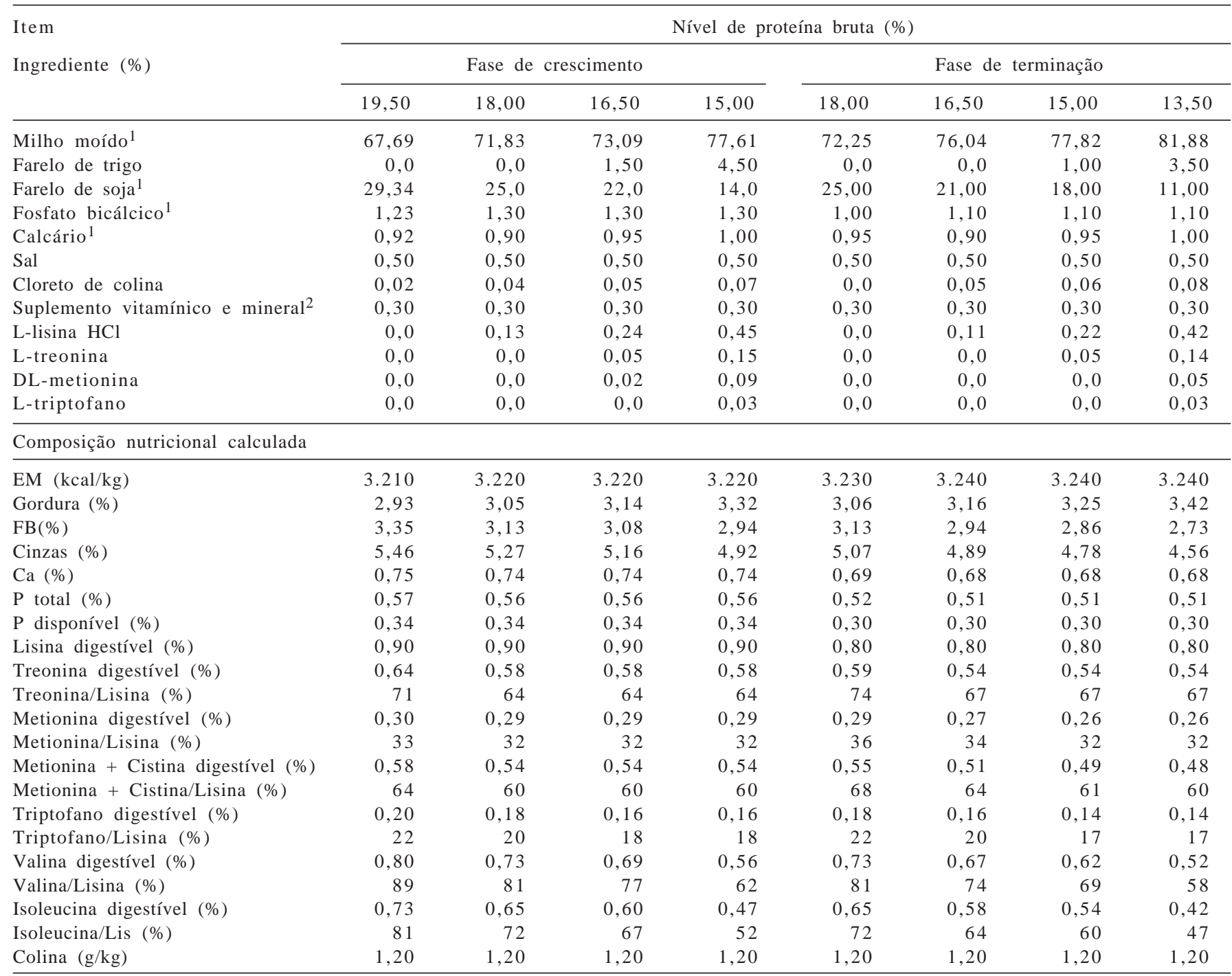

${ }_{1}$ Analisado no Lab. Bromatologia-IZ.

${ }^{2}$ Quantidade/kg de ração: vit. A - 3.000 UI; vit. D3 - 750 UI; vit. E - 5.437 mg; ácido fólico - 0,225 mg; pantotenato de Ca - 6 mg; biotina - 0,019 mg; niacina - $9 \mathrm{mg}$; piridoxina - 0,75 mg; riboflavina - 2,1 mg; tiamina - 0,75 mg; vit. B12 - 11,25 mcg; K3 - 0,375mg; colina - 0,234 g; bacitracina de zinco - 50 ppm; antioxidante - $90 \mathrm{mg}$; Cu - $90 \mathrm{mg} ; \mathrm{Zn}-480 \mathrm{mg}$; I- 5,7 mg; Fe - $300 \mathrm{mg} ; \mathrm{Mn}-210 \mathrm{mg}$, Se - 0,225 mg.

contendo bebedouros do tipo chupeta e comedouros simples, no interior de um galpão de alvenaria, com pé-direito de 3,50 m e janelas do tipo basculante nas laterais para controle da ventilação. $\mathrm{O}$ acesso às instalações era restrito aos funcionários da unidade.

Utilizando-se quatro termômetros de máxima e mínima, foram aferidas as temperaturas diárias no interior das instalações, tomadas na altura de $50 \mathrm{~cm}$ do piso. Os dados meteorológicos da região onde se localiza o laboratório experimental foram obtidos do Instituto Agronômico de Campinas.

As pesagens dos animais para controle do desempenho foram realizadas no início e ao final de cada período experimental. Ao final da fase de terminação, os animais foram abatidos para avaliações das carcaças. A avaliação de carcaça foi realizada segundo as técnicas descritas pela ABCS (1973). Uma quarta medida de espessura de toucinho foi tomada a $6,5 \mathrm{~cm}$ da linha dorsal $\left(\mathrm{P}_{2}\right)$, conforme descrito por Cuthbertson (1968).

As características de desempenho determinadas nas carcaças foram submetidas à análise de regressão por polinômios ortogonais, por meio do SAS (SAS, 1996), segundo o modelo: $Y_{i j}=\mu+A_{i}+B_{j}+e_{i j}$, em que: $Y_{i j}=$ constante associada a todas observações; $\mu=$ média geral da variável; $\mathrm{A}_{\mathrm{i}}=$ efeito do nível de proteína i, em que i = 1, 2, 3 e 4; $B_{j}=$ efeito do bloco $\mathrm{j}$, em que $\mathrm{j}=1,2,3$, 4, 5 e 6; eij = erro aleatório associado a cada observação.

Considerando o peso corporal, o consumo de ração e o preço do suíno ao final de cada fase, determinou-se a margem bruta decorrente da alimentação, segundo Guidoni et al.(1997). 


\section{Resultados e Discussão}

Ao longo da avaliação experimental, as médias climáticas foram: temperatura máxima $30,8^{\circ} \mathrm{C}$; temperatura mínima $18,9^{\circ} \mathrm{C}$; umidade relativa máxima $95,91 \%$; umidade relativa mínima 50,19\%; e temperatura média $26,6 \pm 2,3^{\circ} \mathrm{C}$ no interior do galpão. Esses valores caracterizam situações de ambiente acima da faixa de conforto térmico para animais nas respectivas fases de desenvolvimento.

Não foram caracterizadas diferenças estatísticas $(\mathrm{P}>0,05)$ nas variáveis de desempenho quando os animais foram alimentados com diferentes níveis de proteína (Tabela 2). Essas respostas ratificam a possibilidade de redução do nível protéico da dieta em até $4 \%$ sem prejuízos ao desempenho do suíno, desde que seja feita suplementação dos principais aminoácidos na dieta, conforme observações de Tuitoek et al. (1997a,b), Figueroa et al. (2002), Kerr et al. (2003b) e Shriver et al. (2003). Esses autores enfatizaram que, além de assegurar o bom desempenho dos suínos em crescimento e terminação, a redução da proteína dietética minimiza a excreção de nitrogênio e aumenta a viabilidade econômica da dieta.

Em estudos complementares adotando como referência a exigência de lisina digestível, Noblet $(2003,2005)$ buscou a otimização da proteína dietética e a redução da excreção de nitrogênio e destacou a necessidade de conhecimentos mais acurados sobre a utilização conjunta de energia e proteína, embora a implementação dessa estratégia exija mais estudos sobre o assunto. Ao considerar a ingestão média de lisina estimada neste estudo, os resultados de desempenho estariam próximos aos citados por Noblet

Tabela 2 - Desempenho dos machos castrados na fase de crescimento, segundo o nível de proteína bruta da dieta

\begin{tabular}{|c|c|c|c|c|c|}
\hline \multirow[t]{2}{*}{ Item } & \multicolumn{4}{|c|}{ Nível de proteína (\%) } & \multirow[t]{2}{*}{ CV \% } \\
\hline & 19,50 & 18,00 & 16,50 & 15,00 & \\
\hline Peso inicial, kg & 30,63 & 30,90 & 30,79 & 30,75 & 2,1 \\
\hline Peso final, kg & 60,45 & 60,48 & 62,07 & 61,94 & 4,2 \\
\hline $\begin{array}{l}\text { Ganho de peso } \\
\text { (kg/dia) }\end{array}$ & 0,852 & 0,845 & 0,894 & 0,891 & 8,3 \\
\hline $\begin{array}{l}\text { Consumo de ração } \\
\text { (kg/dia) }\end{array}$ & 2,045 & 2,007 & 2,110 & 2,135 & 9,4 \\
\hline $\begin{array}{l}\text { Ingestão de Lis } \\
\left(\mathrm{g} / \mathrm{dia}^{1}\right)\end{array}$ & 18,40 & 18,06 & 18,99 & 19,21 & 9,4 \\
\hline Conversão alimentar & 2,41 & 2,38 & 2,36 & 2,41 & 7,9 \\
\hline Dias gastos na fase ${ }^{3}$ & 35 & 35 & 35 & 35 & 3,8 \\
\hline Margem bruta devido & 31,55 & 32,63 & 34,85 & 22,84 & - \\
\hline à alimentação $(\mathrm{R} \$)^{2}$ & 11,68 & 11.65 & 12,44 & 8,1 & \\
\hline
\end{tabular}

1 Valor estimado.

${ }^{2}$ Margem representada por animal na média obtida em cada tratamento, ao final da fase.

${ }^{3}$ Valor ajustado com base no ganho de peso até os $60 \mathrm{~kg}$
(2005) para machos selecionados com alta produção de carne dos 25 aos $90 \mathrm{~kg}$.

A dieta com 16,75\% de PB mostrou-se mais economicamente viável se os animais fossem comercializados ao final da fase de crescimento. A redução de 2,62\% de PB desta dieta decorreu da menor inclusão de farelo de soja e esse valor correspondeu a aproximadamente $16 \%$ da proteína calculada. Nas condições deste estudo, em virtude do ganho de peso e dos custos dos ingredientes, a suplementação de lisina, metionina e treonina tornou a dieta mais viável.

Na fase de terminação, semelhante ao ocorrido na fase de crescimento, a ausência de efeito $(\mathrm{P}>0,05)$ dos níveis de PB da dieta ratifica a possibilidade de redução no nível protéico da dieta em até $4 \%$ sem prejuízos ao desempenho do suíno, desde que haja suplementação dos principais aminoácidos (Tabela 3). Essa informação está de acordo com observações de Tuitoek et al. (1997a,b), Figueroa et al. (2002), Kerr et al. (2003b) e Shriver et al. (2003) ao caracterizarem os benefícios da redução protéica com a incorporação de aminoácidos industriais em dietas para suínos nas fases de crescimento e terminação. Essa redução implicaria vantagens ao meio ambiente, considerada a perda de nitrogênio pelos dejetos produzidos pelo animal quando o nível protéico da ração é elevado.

Entre as características de carcaça avaliadas, apenas a espessura de toucinho sofreu efeito $(\mathrm{P}<0,01)$ quadrático dos níveis dietéticos de proteína, segundo a equação $\hat{Y}=26,06497-2,77593 X+0,085219 X^{2}, R^{2}=0,71$. Nesse caso, a estimativa do nível ótimo de proteína seria de 16,29\% na dieta. Ao contrário das variáveis aferidas in vivo, as aferições obtidas na carcaça podem indicar o direcionamento da proteína dietética ou do conjunto de aminoácidos essenciais e não-essenciais nos componentes da massa corporal. Os valores observados na espessura de toucinho no ponto P2, a 6,5 cm da linha dorsal, sugerem o mesmo efeito da variação protéica das dietas. Fuller \& Wang (1990) destacaram que as necessidades de proteína estão associadas aos aminoácidos na formação do tecido muscular, entre outros componentes corporais. O direcionamento da proteína, ou o conjunto de aminoácidos na relação ideal com a lisina, teria implicações no diferencial entre carne e gordura da carcaça. Estas exigências, portanto, estariam acima daquelas estipuladas para ganho de peso, segundo Cromwell et al.(1993). As observações de Friesen et al. (1996) indicaram que aumento do ganho protéico implica diminuição simultânea da deposição lipídica na carcaça. Essa relação inversa estaria associada à melhor utilização dos aminoácidos e, liderado pela lisina, esses aminoácidos destinam-se à síntese preferencial da proteína muscular esquelética nas fases de maior crescimento. 
Tabela 3 - Desempenho dos machos castrados na fase de terminação, segundo os níveis da proteína dietética

\begin{tabular}{|c|c|c|c|c|c|}
\hline \multirow[t]{2}{*}{ Item } & \multicolumn{4}{|c|}{ Nível de proteína (\%) } & \multirow[t]{2}{*}{ CV \% } \\
\hline & 18,00 & 16,50 & 15,00 & 13,50 & \\
\hline Peso inicial, kg & 60,45 & 60,48 & 62,07 & 61,94 & 4,2 \\
\hline Peso final, kg & 98,57 & 97,53 & 100,12 & 99,59 & 4,8 \\
\hline $\begin{array}{l}\text { Ganho de peso } \\
\text { (kg/dia) }\end{array}$ & 0,977 & 0,950 & 0,974 & 0,965 & 8,1 \\
\hline $\begin{array}{l}\text { Consumo de ração } \\
\text { (kg/dia }\end{array}$ & 3,094 & 2,954 & 2,991 & 3,050 & 8,1 \\
\hline $\begin{array}{l}\text { Ingestão estimada } \\
\text { de lisina, g/dia }\end{array}$ & 24,7 & 23,6 & 23,9 & 24,4 & 8,0 \\
\hline Conversão alimentar & 3,17 & 3,12 & 3,03 & 3,16 & 8,4 \\
\hline $\begin{array}{l}\text { Ganho de peso no } \\
\text { período total, } \mathrm{kg} / \mathrm{dia}\end{array}$ & 0,925 & 0,903 & 0,936 & 0,930 & 9,4 \\
\hline $\begin{array}{l}\text { Consumo de ração no } \\
\text { período total, } \mathrm{kg} / \mathrm{dia}\end{array}$ & 2,312 & 2,257 & 2,340 & 2,325 & 10,1 \\
\hline $\begin{array}{l}\text { Conversão alimentar } \\
\text { no período total }\end{array}$ & 2,50 & 2,59 & 2,50 & 2,5 & 7,4 \\
\hline $\begin{array}{l}\text { Idade à terminação } \\
\text { (dias) }\end{array}$ & 136 & 138 & 135 & 136 & 5,0 \\
\hline $\begin{array}{l}\text { Rendimento de } \\
\text { carcaça (\%) }\end{array}$ & 76,91 & 81,77 & 79,00 & 80,41 & 2,7 \\
\hline $\begin{array}{l}\text { Comprimento de } \\
\text { carcaça }(\mathrm{cm})\end{array}$ & 97,4 & 94,0 & 96,8 & 93,4 & 2,3 \\
\hline Peso de pernil (kg) & 11,64 & 12,27 & 11,90 & 11,71 & 5,2 \\
\hline $\begin{array}{l}\text { Rendimento de pernil } \\
(\%)\end{array}$ & 31,81 & 31,43 & 31,03 & 30,48 & 5,3 \\
\hline $\begin{array}{l}\text { Espessura média de } \\
\text { toucinho }(\mathrm{mm})^{1}\end{array}$ & 18,4 & 19,1 & 18,2 & 21,5 & 8,9 \\
\hline $\begin{array}{l}\text { Espessura de toucinho } \\
\text { P2 }(\mathrm{mm}) 6,5 \mathrm{~cm} \mathrm{da} \\
\text { linha do dorso }\end{array}$ & 13,9 & 16,5 & 14,2 & 18,5 & 16,1 \\
\hline $\begin{array}{l}\text { Área de olho-de- } \\
\text { lombo }\left(\mathrm{cm}^{2}\right)\end{array}$ & 38,8 & 40,6 & 39,1 & 38,6 & 10,5 \\
\hline Margem bruta & 28,01 & 28,97 & 30,70 & 20,30 & - \\
\hline $\begin{array}{l}\text { atribuída à } \\
\text { alimentação }(\mathrm{R} \$)^{2}\end{array}$ & 10,00 & 10,35 & 10,96 & 7,25 & \\
\hline
\end{tabular}

1 Efeito quadrático.

${ }^{2}$ Margem representada por animal na média obtida em cada tratamento ao final da fase.

A ausência de efeito do nível protéico das dietas sobre a concentração de lisina digestível, como observado neste estudo, pode ter limitado a síntese muscular por dois fatores: a própria demanda, uma vez que o consumo insuficiente de aminoácido prejudica a utilização dos demais aminoácidos essenciais; e o custo energético na eliminação metabólica dos aminoácidos, essenciais ou não-essenciais, quando se encontram fora das relações demandadas com a lisina para o ganho muscular. Em ambas as situações, a retenção protéica é praticamente constante (Friesen et al., 1996; Schinckel \& Lange, 1996; Van Lunen \& Cole, 1998; Trindade Neto et al., 2004).

Na comparação dos resultados da margem bruta atribuída à alimentação, a dieta com 15,00\% de PB propiciou maior retorno financeiro na comercialização dos machos castrados à terminação. Essa viabilidade econômica decorreu da redução de 2,44\% da PB, em comparação ao maior nível protéico estudado, ou da diminuição de $28 \%$ do farelo de soja. Considerando o ganho de peso e o custo dos ingredientes básicos, a suplementação de lisina e treonina tornaram essa dieta mais rentável. Assim, o conceito de dieta comercial deve ser aplicado na produção e no custo final do suíno comercializado para o abate (Noblet, 2003; Shriver et al., 2003).

A indicação do nível protéico de 16,50\% para machos castrados, com base na avaliação econômica ao final da fase de 30 a $60 \mathrm{~kg}$, comprovou ser vantajosa a inclusão dos aminoácidos livres: lisina, treonina e metionina no ajuste das demandas nutricionais na fase de crescimento. Os dados médios obtidos com essa categoria suína nesse intervalo foram: $871 \mathrm{~g} /$ dia no ganho de peso e 2,39 na conversão alimentar. Além de a fase de crescimento ser a de maior ascensão na deposição protéica, independentemente do sexo, as condições aplicadas ao estudo devem ser consideradas como provável fator determinante na similaridade das respostas.

Na terminação dos machos castrados, a ausência de efeitos expressivos no desempenho, com os níveis protéicos estudados, caracterizou a viabilidade na redução do conteúdo de proteína da dieta ao nível 13,50\%, com suplementação dos quatro principais aminoácidos. A menor espessura de toucinho e a maior margem bruta atribuída à alimentação, contudo, foram obtidas quando as dietas foram suplementadas com lisina e treonina e apresentavam 16,29 e 15,36\% de proteína, respectivamente. As médias gerais obtidas nessa fase (61 aos $99 \mathrm{~kg}$ ) foram $967 \mathrm{~g} /$ dia no ganho de peso e 3,12 na conversão alimentar.

A mínima variação da energia dietética, com a proximidade dos níveis digestíveis dos principais aminoácidos, foi suficiente para assegurar o bom desempenho dos animais e a ausência de diferenças $(\mathrm{P}>0,05)$ entre os tratamentos experimentais no desempenho. Como não foi caracterizado excesso nutricional com prejuízos ao metabolismo do suíno em crescimento e terminação, a variação no consumo individual de ração foi suficiente para estabilizar o ganho de peso, sobretudo na fase de terminação, quando a eficiência da síntese protéica foi superada pela síntese lipídica. Assim, além da viabilidade econômica, a retenção de nitrogênio na caracterização da carcaça e o impacto ambiental devem ser avaliados em estudos desta natureza.

\section{Conclusões}

Nos níveis testados, a diminuição da proteína dietética com a suplementação dos principais aminoácidos não prejudicou o desempenho de machos castrados nas fases de crescimento e terminação criados em condições desejáveis 
de saúde, segregados, em sistema de produção comercial. Os melhores resultados econômicos na fase de crescimento, no entanto, foram obtidos com dietas contendo 16,5\% de PB suplementadas com lisina, treonina e metionina e, na fase de terminação, com dietas contendo 15,00\% de PB suplementadas com lisina e treonina.

\section{Literatura Citada}

ASSOCIAÇÃO BRASILEIRA DE CRIADORES DE SUÍNOS - ABCS. Método brasileiro de classificação de carcaça. Estrela: 1973. $17 p$.

CROMWELL, G.L.; CLINE, T.R.; CRENSHAW, J.D. et al. The dietary protein and (or) lysine requirements of barrows and gilts. Journal of Animal Science, v.71, n.6, p.1510-1519, 1993.

CUTHBERTSON, A. PIDA dissection techniques. In: SYMPOSIUM ON METHODS OF CARCASS EVALUATION, 1968, Dublin. Proceedings... Dublin: European Association for Animal Production, 1968. 8p.

FIGUEROA, J.L.; LEWIS, A.J.; MILLER, P.S. et al. Nitrogen metabolism and growth performance of gilts fed Standard cornsoybean meal diets or low-crude protein, amino acidsupplemented diets. Journal of Animal Science, v.80, n.11, 2911-2919, 2002.

FRIESEN, K.G.; NELSSEN, J.L.; GOODBAND, R.D. et al. The use of compositional growth curves for assessing the response to dietary lysine by high-lean growth gilts. Animal Science, v.62, n.1, p.159-169, 1996.

FULLER, M.; WANG, T.C. Digestible ideal protein - a measure of dietary protein value. Pig News Information, v.11, n.3, p.353-357, 1990.

GUIDONI, A.L.; ZANOTTO, D.L.; BELLAVER, C. Método alternativo na análise bioeconômica de experimentos com alimentação de suínos. In: REUNIÃO ANUAL DA SOCIEDADE BRASILEIRA DE ZOOTECNIA, 34., 1997, Juiz de Fora. Anais... Juiz de Fora: Sociedade Brasileira de Zootecnia, 1997. p.106-108.

JONGBLOED, A.W.; LENIS, N.P. Alteration of nutrition as a means to reduce environmental pollution by pigs. Livestock Production Science, v.31, n.1/2, p.75-94, 1992.

KERR, B.J.; SOUTHERN, L.L.; BIDNER, T.D. et al. Influence of dietary protein level, amino acid supplementation, and dietary energy levels on growing-finishing pig performance and carcass composition. Journal of Animal Science, v.81, n.12, p.30753087, 2003a.

KERR, B.J.; YEN, J.T.; NIENABER, J.A. et al. Influence of dietary protein level, amino acid supplementation on environmental temperature on performance, body composition, organ weights and total heat production of growing pigs. Journal of Animal Science, v.81, n.8, p.1998-2007, 2003b.

MINISTÉRIO DA AGRICULTURA E REFORMA AGRÁRIA, SECRETARIA NACIONAL DE DEFESA AGROPECUÁRIA,
Departamento Nacional de Defesa Animal, instrução técnica DNDA no 001/92, de 26 de março de 1992. Assunto: exigências sanitárias para certificação de granjas de suínos com um Mínimo de Doenças -GSMD.

NOBLET, J. Impact of dietary crude protein on metabolic utilization of energy in pigs. [2003]. Disponível em: <http: www.engormix.com/e_articles.asp?ID=100> Acesso em: 14/1/ 2006.

NOBLET, J. Protein and energy requirements of growing swine. In: SIMPÓSIO INTERNACIONAL SOBRE EXIGÊNCIAS NUTRICIONAIS DE AVES E SUÍNOS, 2., 2005, Viçosa, MG. Anais... Viçosa, MG: Universidade Federal de Viçosa, 2005. p.175-198.

OTTO, E.R.; YOKOYAMA, M.; KU, K.P. et al. Nitrogen balance and ileal amino acid digestibility in growing pigs fed diets reduced in protein concentration. Journal of Animal Science, v.81, n.7, p.1743-1753, 2003

ROSTAGNO, H.S.; SILVA, D.J.; COSTA, P.M.A. et al. Composição de alimentos e exigências nutricionais de aves e suínos (Tabelas brasileiras). Viçosa, MG: Universidade Federal de Viçosa, 2000. 141p.

STATISTICAL ANALYSIS SYSTEM - SAS. User's guide: statistics. Version 6.12. Cary: 1996.

SCHINCKEL, A.P.; LANGE, C.F.M. Characterization of growth parameters needed as inputs for pig growth modes. Journal of Animal Science, v.74, n.8, p.2021-2036, 1996.

SHRIVER, J.A.; CARTER, S.D.; SUTTON, A.L. et al. Effects of adding fiber sources to reduced-crude protein, amino acidsupplemented diets on nitrogen excretion, growth performance, and carcass traits of finishing pigs. Journal of Animal Science, v.81, n.2, p.492-502, 2003.

STAHLEY, T. Nutrition affects lean growth, carcass composition. Feedstuffs, v.65, n.26, p.12/23, 1993.

TRINDADE NETO, M.A.; BARBOSA, H.P.; PETELINCAR, I.M. Níveis de lisina para leitões na fase inicial-1 do crescimento pós-desmame: composição corporal aos 11,9 e 19,0 kg. Revista Brasileira de Zootecnia, v.33, n.6, p.1777-1789, 2004.

TUITOEK, J.K.; YOUNG, L.G.; DE LANGE, C.F.M. et al. The effect of reducing excess dietary amino acids on growingfinishing pig performance: an evaluation of the ideal protein concept. Journal of Animal Science, v.75, n.6, p.1575-1583, 1997.

Van LUNEN, T.A.; COLE, D.J.A. The effect of dietary concentration and lysine/digestible energy ratio on growth performance and nitrogen deposition of young hybrid pigs. Animal Science, v.67, n.1, p.117-129, 1998.

WILLIANS, N.H.; STAHLY, T.S.; ZIMMERMAN, D.R. Effect of chronic immune system activation on body nitrogen retention, partial efficiency of lysine utilization, and lysine needs of pigs. Journal of Animal Science, v.75, n.9, p.2472-2480, 1997a.

WILLIANS, N.H.; STAHLY, T.S.; ZIMMERMAN, D.R. Effect of chronic immune system activation on on the growth and dietary lysine needs of pigs fed from 6 to $112 \mathrm{~kg}$. Journal of Animal Science, v.75, n.9, p.2481-2496, 1997b. 